
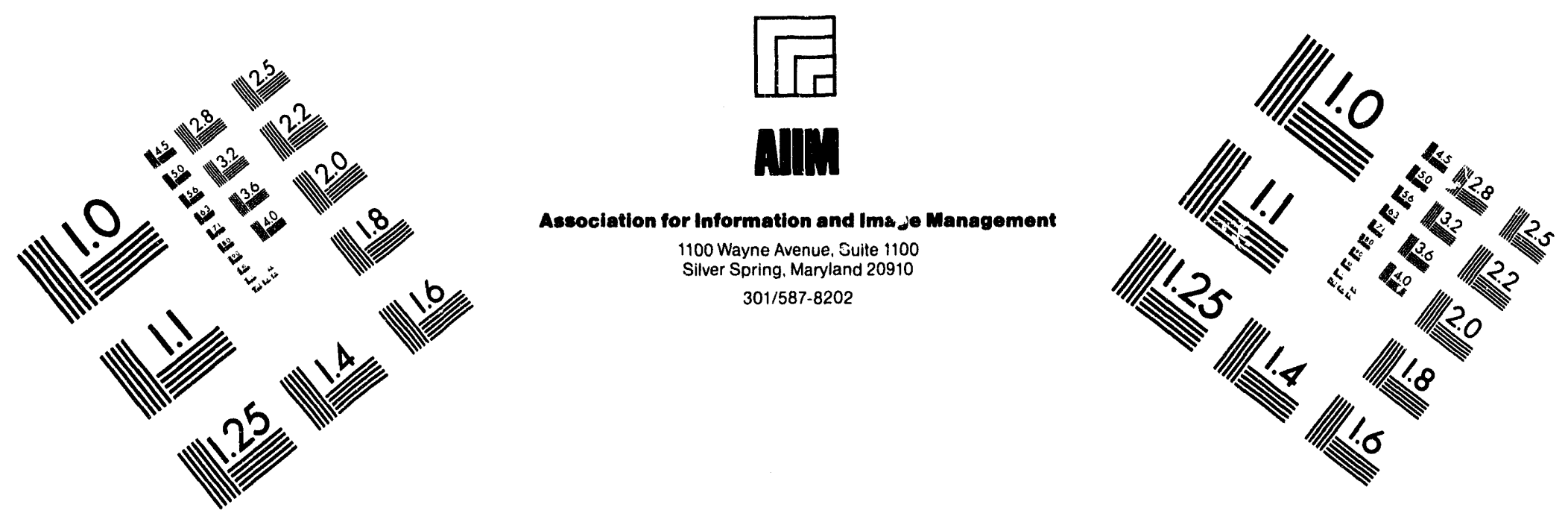

\title{
Centimeter
}

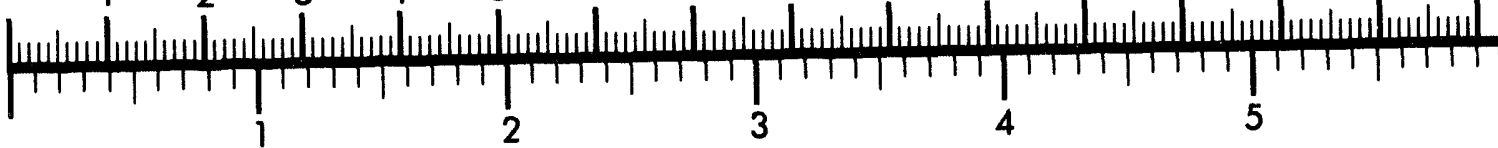
Inches
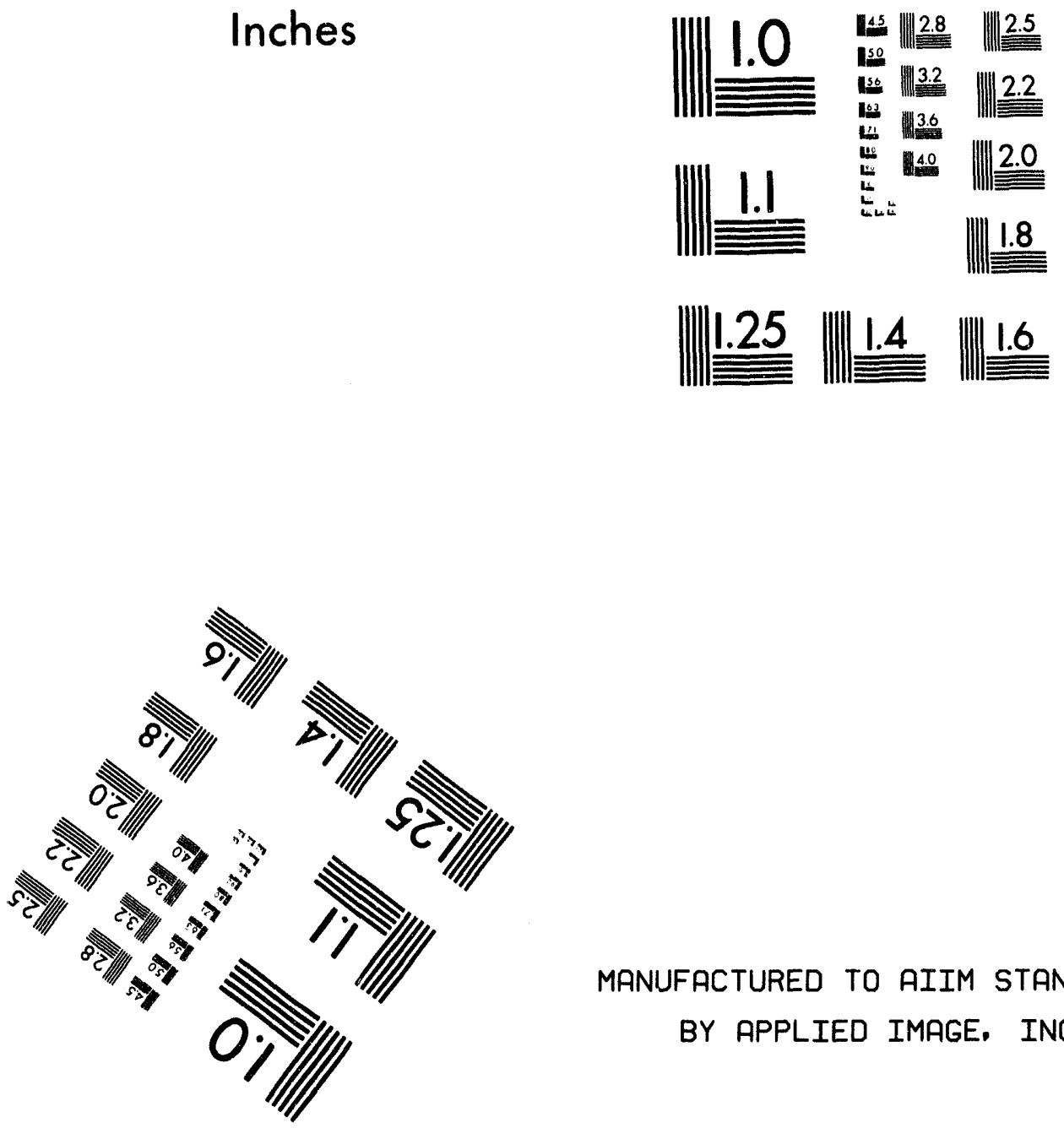

MANUFACTURED TO AIIM STANDARDS

BY APPLIED IMAGE, INC.

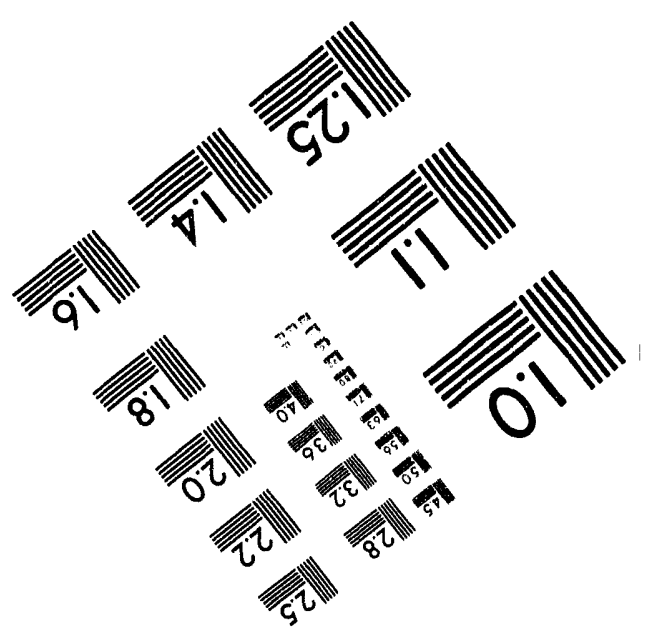


:
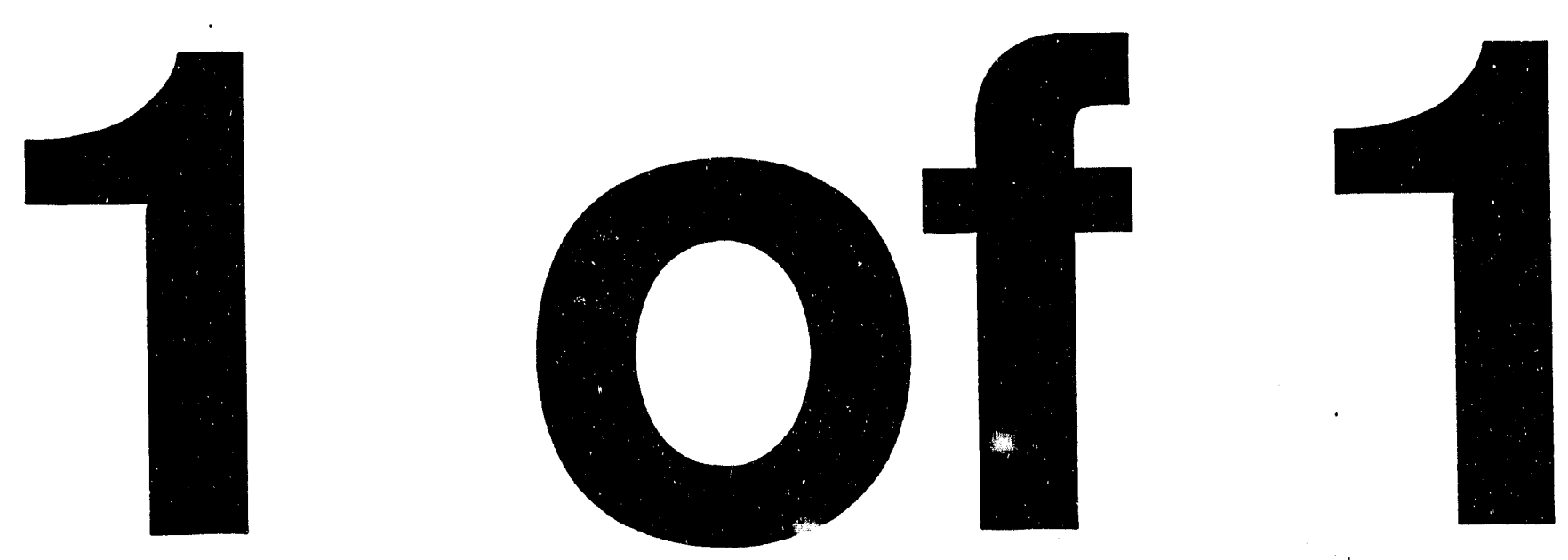


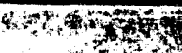

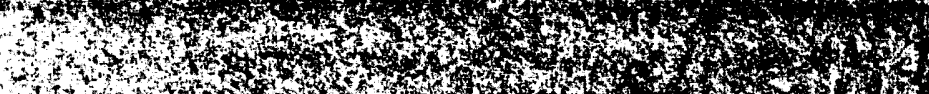

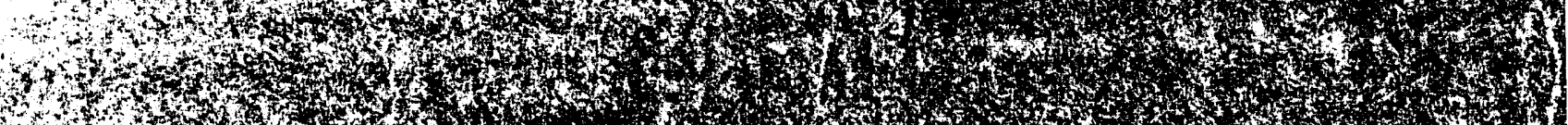

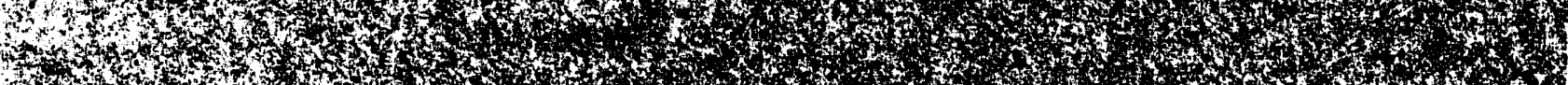

r.t. 1.t. ,

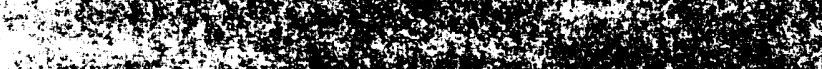

ntw

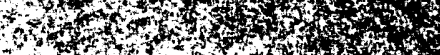

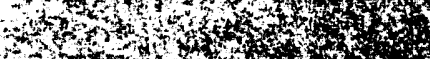

How

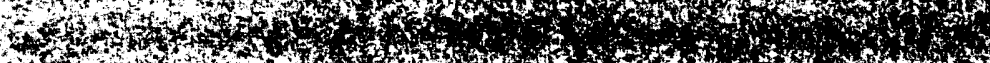

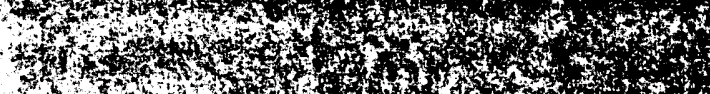

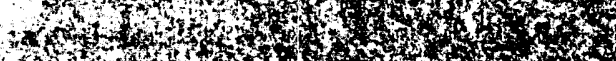

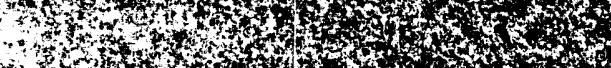

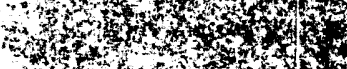

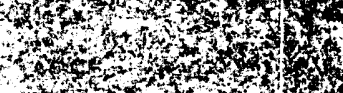

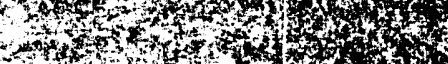

$3+6,6)$

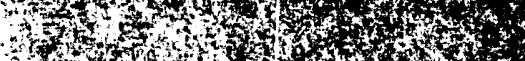

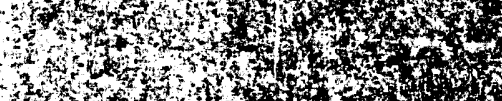

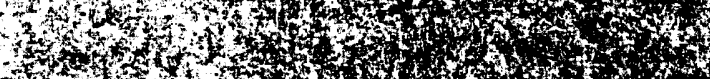

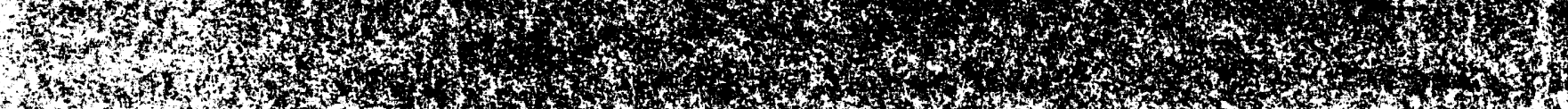

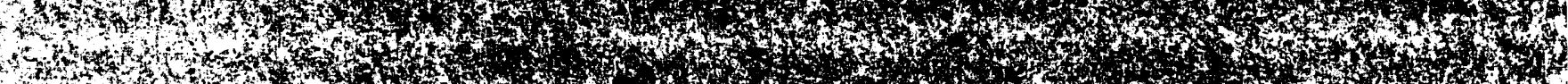

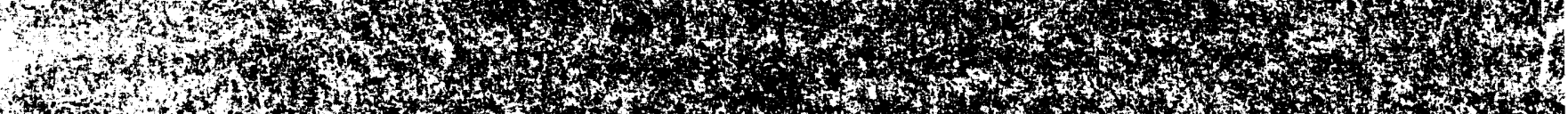

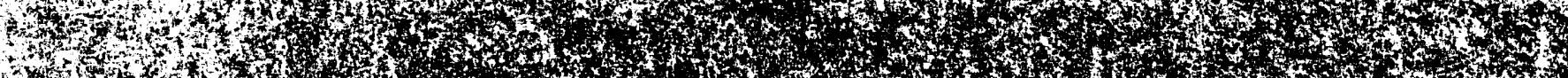

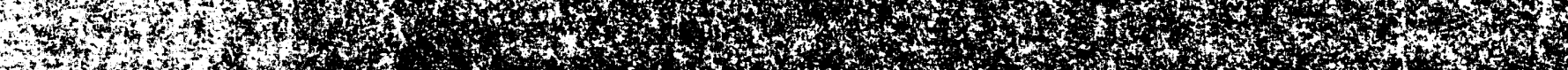
3.

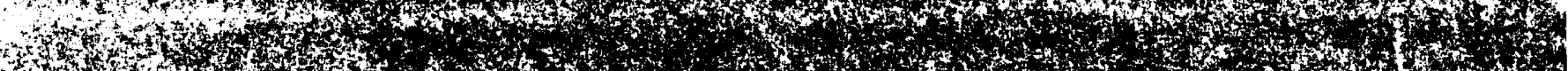
167, 3
1

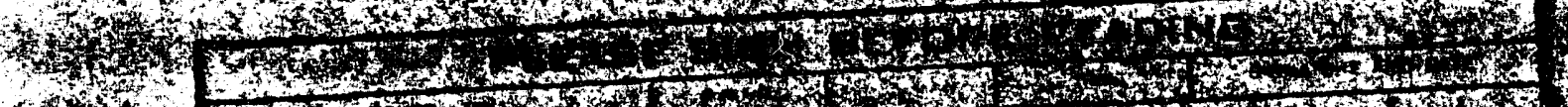

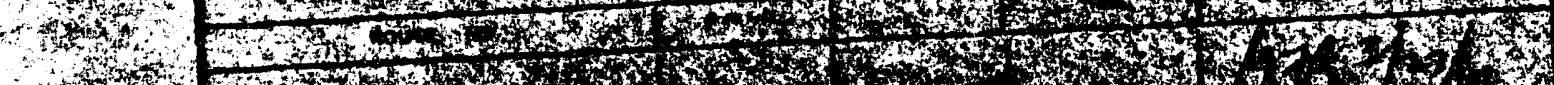

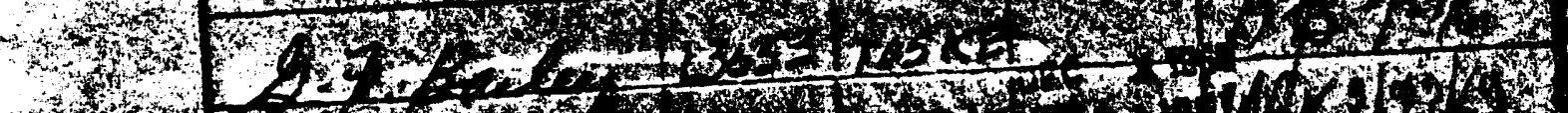

+ 13x

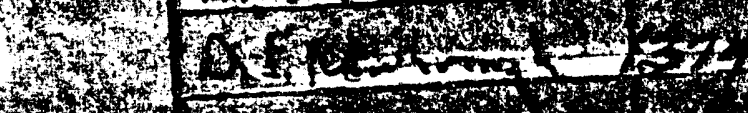

3)

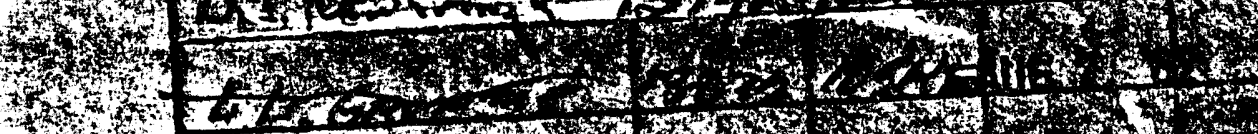

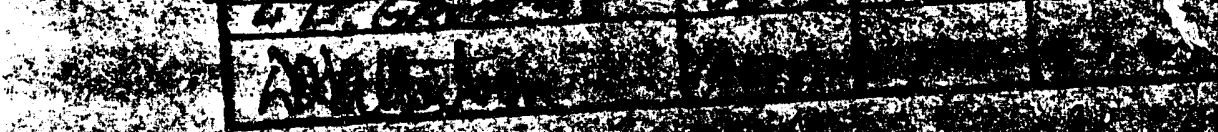

कर,

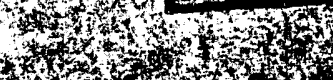

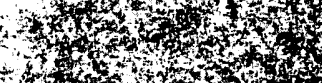

3)

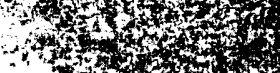

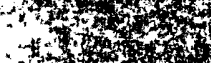

2.

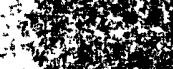

$+\frac{1}{4}$

3xty 


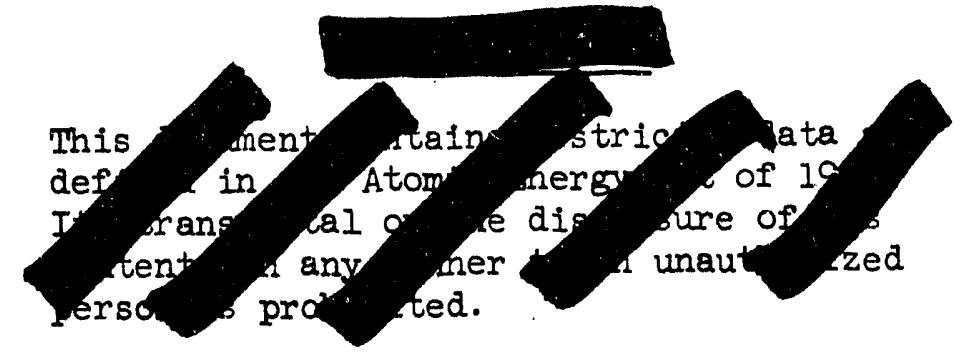

This document classified

This document consists

ny: Hc Fullmen

of 34 pages. No. 3 of 76 copies.

REVIEW MATERIAL ON CHAPTTER V

CONTROL OF THE PILE REACTION

REACTOR PROCESSING FUNDAMENTAIS COURSE

Crumition Concalod and Changed To OECLISSFFIED

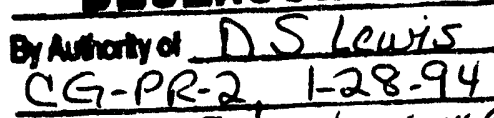

$\frac{C G-P 1-2,1-28-94}{\text { B S Savely } 2+14-94}$ November 21, 1960 viriad Bx forrimales

$$
2 \frac{24.94}{2.24}
$$

By:

E. H. Lockwood

DISTRIBUTION
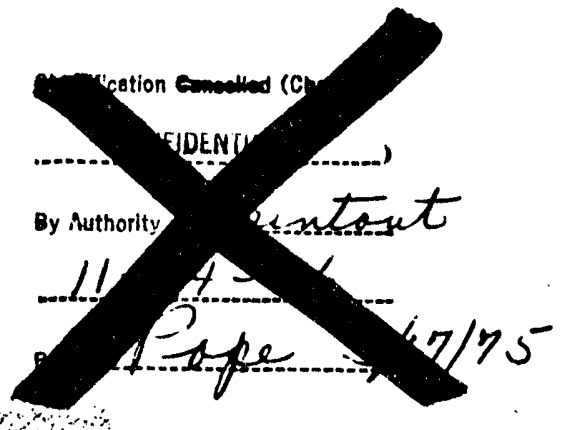

1-2. JT Baker

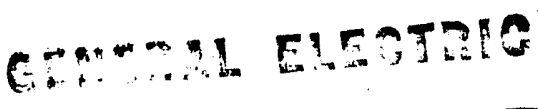
$\ldots$

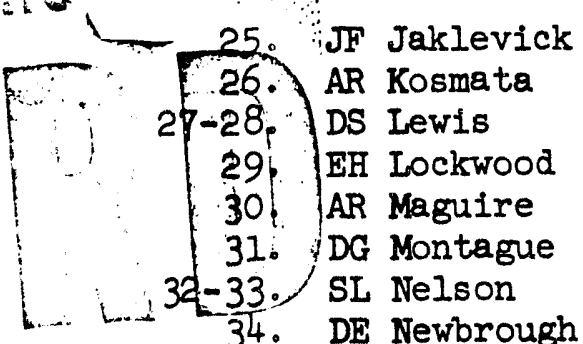

$11-12$.

10. RA Ghitwood

13. DN donstable

14. JH Ferguson

15-16. WJ Ferguson

17. EJ Filip

18. GC Fullmer

19-20. WJ Gartin

21. OH Greager

22. CN Gross

23. AK Hardin

24. TW Hauffefinite Ru: indion Risiosal Date

35. GF Owsley

36. RW Re1a

37. WD Richmond

38. SL Stewart

39-40. AP Vinther

41. CD Wilkinson

42-74. Extra

75. 300 File

76. Records Center Authority

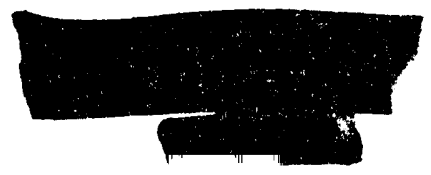




\section{Imax DELLSSIFIED}

\section{CHAPIER V - CONIROL OF THE PIIE REACTION}

The index below is arranged numerically by page number for quick reference to. specific information concerning the subjects covered in this review.

Pages

1. Review $-k$, critical mass, periods ........... 1-9

2. Review - Temperature, Xenon, and Exposure Effects ...... 9-13

3. Control of Preceding Reactivity Changes (Transients) - Size and Timing of Transients, Compensating Control Required . . . 13-15

4. Operating Safety - Rod Withdrawal Rates, Poison Discharge, Safety Backup .................. 15-17

5. Total Control - Requirements and Provisions . . . . . . 17-18

6. Review - Flattening, Temperature Balance, Total Power output 18-20

7. Temperature Distribution - Local Flux Trends, "Small Pile"

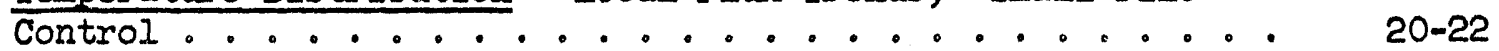

8. Temperature Cycling - Importance of Trend Monftoring, Early Detection, Accurate Analysis, Timely Action . . . . . . 22-24

9. Supplementary Control Flexibility - Ges Composition, Splines and PCCF, Level Adjustment ............ 24-26

10. Trend Instrumentation - Validity of Reading, Crosschecks - - 26-27

11. Distribution Control During Startup - Startup Level, Turnaround Distribution, Approach to Equilibrium Configuration . . . . 27-28

12. Summary Questions on Distribution Control Know-how - Instrumentation, Trend Monitoring, "Small P1le" Control ...... 28-34 
REVIEW MATERIAL ON CHAPTIER V CONIROI OF THE PILE REACTION

\section{REACTOR PROCESSTIVG FUNDAMENTALS COURSE}

This document is the third of a series of question and answer lists issued as a review of the material discussed in the Reactor Processing Fundamentals Course. The first list, HW-59145, "Review Material on Chapter III - Pile Structure," was issued June 8, 1959. The second, HW-65248, "Review Material on Chapter IV - Variations in Pile Reactivity," May 23, 1960. Each document represents the material covered by the Reactor specialists during a typical three-month training program. Each question is discussed individually and the entire list completed during the three-month session. Each three-month training period is devoted to the complete discussion of a single chapter of the IPD Physics Primer series.

The questions are compiled in a logical sequence with the material as presented in Chapter V of the Primer series. As the course progresses, a certain amount of recall of earlier chapters is essential to a thorough knowledge of the specifics of reactivity and distribution control. Therefore, the first half of this document consists of material previously presented in a slightly different manner. The second half also may contain questions of a repetitious nature - used at this point to drill home the fine points of local trend control. Basic points are stressed; the intent is, of course, that informative discussions lead to a better understanding of the material presented in the Primer. At the completion of each threemonth period, each participating member receives a complete review in this documentary form which may prove useful as a training guide for shift group training meetings.

A typical three-month training program consists of three (3) three and one-half hour discussion periods on a single chapter of the IPD Physics Primer series (ten and one-half hours total). The meetings are held every Wednesday from 8:00 to $11: 30 a_{0} m_{0}$, at the $105 \mathrm{KE}$ Conference Room, with each of the four shift classes meeting monthly. At the time Specialist classes have covered the following:

Chapter I - Structure of the Atom

Chapter II - Physical Principles of the Reactor Process

Chapter III - The Pile Structure and Instrumentation

Chapter IV - Variations in Pile Reactivity

Similar training programs will be offered on the two remaining chapters of the Primer series:

Chapter V-Control of the Pile Reaction

Chapter VI - Operating Procedures and Standards (in preparation)

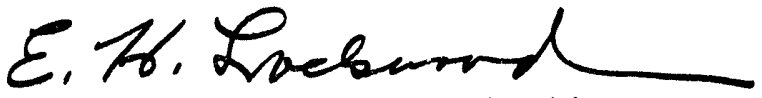

Operational Physics Sub-Section

Research and Engineering Section IRRADIATION PROCESSING DEPARTMENT

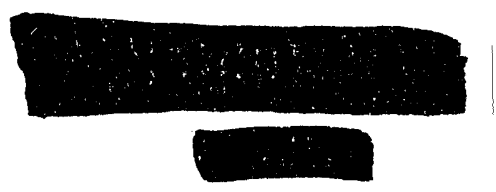




\section{REACTOR FUNDAMENTALS TRATNING QUESTIONS}

\section{CHAPTER V \\ CONIROL OF THE PILE REACTION}

1. Are all neutrons produced in fission avallable to cause other fission reactions? Explain.

Answer: Only a fraction (about 4 of every 10) of the fission neutrons are avallable to produce another fission; some are lost in captures which do not produce fission, in coolant, moderator and structural material, and some leak from the edges of the pile.

2. Name four neutron processes that affect the value of the "multiplication factor" in the Hanford (or any) reactor.

Answer: 1. Complete loss of fast or slow neutrons by escaping from the pile.

2. Non-fission capture by $U^{238}$.

3. Non-fission capture by coolant, moderator, fission products, etc.

4. Fission capture of slow neutrons by $U^{235}$, or of fast neutrons by both $U 235$ and $U 238$.

3. What is the fast fission effect?

Answer: Before the velocity of the newly-created fast neutrons is decreased to any great extent, they will cause a few fast fissions in the more abundant UR38 nucle1, and also a negligible number in the relatively scarce $U 235$ nucle1. This effect is called the "fast fission" factor and it multiplies the number of neutrons created by thermal fissions each generation by a value slightly in excess of unity (about 1.03). In other words three per cent additional neutrons are produced in this way.

4. When newly created fast neutrons enter the graphite: (a) what is the initial speed of the fast neutron, (b) about how many collisions are required to reduce the speed to "slow" or "thermal" values, (c) how long is the neutron life cycle, or generation time, (d) what is the approximate rate of travel of a slow (thermal) neutron?

Answer: (a) An energy of about $2 \mathrm{Mev}$ is equivalent to a speed of 18,000 miles/second, about $10 \%$ the speed of light. (b) About 115 collisions, (c) about 0.001 second, and (d) mare than 3000 miles per hour.

5. Assuming optimistically that three neutrons are produced in each fission reaction, describe a possible three-term neutron balance for a multiplication of exactly unity, or keff $=1.0000$. 
5. (Continued)

Answer: One of the three fission neutrons garries on the fission chain with U235, another is captured by a 238 nucleus to form plutonium, while the third is lost, either in other forms of non-fission capture or by escape from the pile.

6. What is the primary method of controlling the neutron population in a Hanford reactor?

Answer: The primary method of controlling the neutron population, and thus the power output of the reactor, is to control the parasitic capture reactions. This is accomplished by inserting into or withdrawing from the reactor a rod of neutron absorbing materlal that readily absorbs neutrons, but does not in turn liberate new neutrons.

7. What is meant by the statement: Production = absorption plus leakage?

Answer: The statement describes the neutron balance for a steady state condition where the number of neutrons produced is equal to the total number lost by absorption and leakage. When the chain reaction is steady and exactly self-sustaining, such a system is said to be "critical." This means that the system is perfectly balanced in rate of neutron replacement relative to losses.

8. What is the relationship between the multiplication factor and an increase in power output?

Answer: Since the power level of a given reactor is directly proportional to the neutron density or flux, the only practical way to increase this density is to make use of a rising fission chain reaction, for which

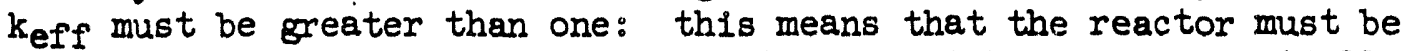
built with enough potential reactivity so that keff can potentially exceed unity. However, once the power increase is attained, the $k_{\text {eff }}$ must be returned to and maintained at exactly 1.0000 .

9. What term is used to describe the amount by which a multiplication factor is greater than unity?

Answer: The amount by which the multiplication exceeds one is called the "excess multiplication factor," or excess $\mathrm{k}$, and is usually expressed in terms of per cent of the multiplication factor. For example, a multiplication factor of 1.01 corresponds to an excess $k$ of 0.01 , or one per cent. Since $k_{\text {eff }}=1$ for a just critical reactor, $k_{e x}$ is a measure of departure from this condition. Numerically then: $\mathrm{k}_{\mathrm{ex}}=\mathrm{k}_{\mathrm{eff}}-1$.

10. Are there any neutrons in the shutdown reactor? 


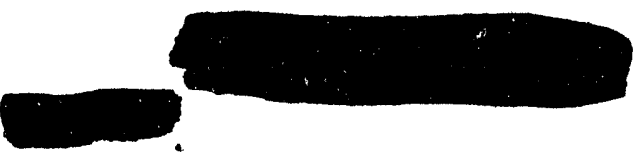

10. (Continued)

Answer: Even when shut down, every Hanford reactor has a residual neutron density. These may come from the spontaneous fission of uranium, from fission caused by cosmic rays, or from other sources such as the fission decay gama reaction with the deuterium in the cooling water. As long as the system is subcritical (keff $<1$ ) the neutron flux will be quite small and will remain constant at a level depending on the degree of subcriticality.

11. How is the neutron density of the shutdown reactor changed during startup and the following rise to operating level?

Answer: By withdrawing the neutron-absorbing control rods, the parasitic capture of neutrons is reduced so that $\mathrm{k}_{\mathrm{eff}}$ becomes greater than one and the rising chain reaction causes the neutron density to increase until the desired power level is attained. The control rods are then partially inserted to absorb enough neutrons to make $k_{\text {eff }}$ equal to unity; the chain reaction now becomes steady and the power level remains constant.

12. Are all fission neutrons released at the instant of fission? Explain.

Answer: All neutrons produced by fission are not released at the instant of fission. Over 99 per cent of the neutrons are released within an extremely short interval of time; these are referred to as "prompt neutrons." The remainder, about $3 / 4$ of one per cent of the neutrons, are "delayed neutrons" which are ejected from the fission products a few seconds after the actual fission occurs.

13. Are delayed neutrons ejected from a single fission product? What are the delay times?

Answer: The delayed neutrons accompanying the fission of uranium-235 and plutonium-239 fall into five major groups, each of which is detected by a definite rate of decay. The rates of decay range from 0.6 to 80 seconds and average about 10 seconds.

14. What effect do delayed neutrons have on reactor startup? Shutdown?

Answer: Since the prompt fission neutrons are released almost instantaneously, the generation time as far as these neutrons are concerned, is onethousandth of a second. However, when the delayed neutron time of roughly one per cent of the neutrons is averaged with the lifetime of the 99 per cent prompt neutrons, the effective generation time is changed from one-thousandth of a second to one-tenth of a second. When the reactor is shut down, the large number of delayed neutrons cause the power to drop off slowly rather than instantaneously. If there were no such thing as the delayed neutron effect, the neutron generation time in the graphite reactor would be about one-thousandth of a second, and there would be a constant danger of the reaction being too fast for human control. 
15. How can a "prompt critical" condition be avoided?

Answer: If the delayed neutron effect sets the effective neutron lifetime as 0.1 seconds, it follows that for a reaction that is just barely critical ( $k_{\text {eff }}=1.000$ ), the rate of neutron population increase or decrease will be determined by the average neutron emission time of 0.1 second. Since the delayed neutron effect is 0.75 per cent, or a fraction 0.0075 of the total, prompt critical can be avolded provided the multiplication factor is kept between 1.0000 and 1.0075 . In other words, the control rods should be withdrawn in steps so that at criticality, the keff is less than 1.0075, but greater than 1.0000. If criticality can be attained with keff slightly in excess of 1.0000 , the neutron population can increase only through the additional contribution from the delayed neutrons.

16. What would occur if criticality were attained with a $k_{\text {eff }}$ of 1.0075 ?

Answer: The reactor would be critical on prompt neutrons alone and would increase without waiting for any delayed neutron effect. The combination of $k_{\text {eff }} 1.0075$ and the $1 / 1000$ second generation time would cause the chain reaction to increase at a tremendous rate. At the defined pcint of "prompt critical," the reactor period would be of the order of one second.

17. From Figure 4, give the rate of increase for: (a) k excess of 0.001 , (b) $k$ excess of 0.0075 , and (c) $k$ excess of 0.015 .

Answer: (a) 46 seconds for the neutron flux to increase by a factor of $\mathrm{e}(2.718),(3) 0.7$ seconds (prompt critical), and (c) 0.2 second.

18. What is the relationship between the length of the pile period, the per cent of excess $k$, and the inhour (or c-mk) 8

Answer: A given amount of excess reactivity will cause the neutron flux to increase at a given rate. The rate of this increase can be measured with time and converted to elther inhours or units of $k$ (such as $c-m k)$. The theoretical relation between inhours and excess $k$ Indicates that one per cent of excess corresponds to approximately 400 inhours. Thus prompt critical or 0.75 per cent excess $\mathrm{k}$ is equivalent to almost 300 inhours. Using this assumption, we can convert $k$ excess to Inhours thus:

$$
\text { Inhours }=40000 \times \frac{K_{\text {ex }}}{K_{\text {eff }}}
$$

The table below shows the relative values of $k$ effective, $k$ excess in per cent and in inhours, and the corresponding pile periods in seconds. 
18. (Continued)

Answer: (Continued)

Reactivity and Pile Period

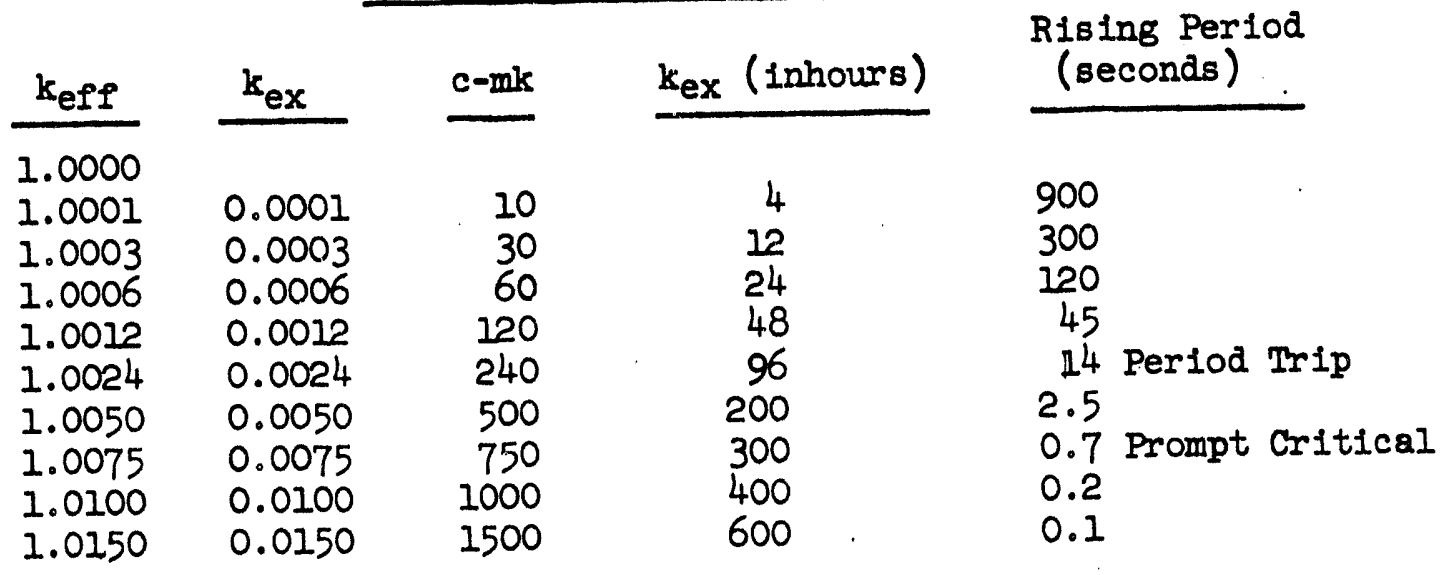

19. Should the $k_{\text {eff }}$ of a reactor operating at a steady $100 \mathrm{MW}\left(\mathrm{keff}_{\mathrm{f}}=1\right)$ be suddenly increased by a rod pull representing $240 \mathrm{c}$-mk of $\mathrm{k}$ excess, the power level would increase by a factor of $e$ in 14 seconds. If allowed to continue, what would the level be in 14 seconds, in 28 seconds, in 42 seconds, and in 56 seconds?

Answer: 14 seconds after rod pull the power would be $100 \times 2.718=271.8 \mathrm{MW}$, at 28 seconds $271.8 \times 2.718=739 \mathrm{MN}$, at 42 seconds $2,010 \mathrm{MW}$, and 56 seconds $5,465 \mathrm{MW}$.

20. How can fast rising periods be avoided during reactor startup?

Answer: During reactor startup the exponential rate of increase can cause the level to rise to dangerous proportions if allowed to continue unchecked for even a few minutes. The inherent danger of fast rising periods must be considered carefully in the approach to criticality. By correct regulation of the rod withdrawal rate, in accordance with procedure alone or including subcritical monitoring, the amount of excess $k$ can be controlled so that after criticality the rising period will be sufficlently long to provide time for accurate measurement of the supercritical rate of rise. In other words, the reactor should enter the supercritical stage with only that amount of excess $k$ necessary to generate a reasonable and safe pile period.

21. From F1gure 5, give the rate of increase for the following amounts of $k$ excess: (a) 0.0023 , (b) 63 inhours, (c) $120 \mathrm{c}$-mk, (d) 40 inhours, (e) 0.0007 , (f) 24 inhours.

Answer: (a) 15 second period, (b) 30 second period, (c) 45 second period, (d) 60 second period, (e) 90 seconds, (f) 120 seconds. 
22. What are the requirements of an "Ideal" horlzontal control rod system?

Answer: 1. An 1deal horizontal control rod system would be perfectly calibrated for total control capac1ty and incremental rod strength, and would provide adequate control for safe and steady operation of the reactor under all possible reactivity conditions.

2. It would be able to completely control any reactivity transient or flux distortion arising from startups, turnaround, power level changes, or changes in gas composition.

3. It should provide fast-moving controls for the adjustment of extremely short pile periods, for scram recoveries and emergency shutdowns, and yet it should be capable of fine adjustment control during equilibrium operation.

4. It should be flexible enough to obtain maximum flattening and flux distribution adjustment ability from the amount of excess reactivity available.

\section{Do the Hanford reactor control systems satisfy these requirements?}

Andwer: No, the horizontal rod systems alone at any of the reactors falls far short of an ideal system. Certain provisions are made that provide adequate control, but they fail to meet the requirements for ease of control.

24. What provisions were made to supplement the present horizontal control rod systems?

Answer: To improve the flexibility of the horizontal rod systems for uniform flattening and to increase the total control capacity, the five older reactors ( $B, D, D R, F, H)$ are equipped with the Poison Column Control Facility (PCCF) which permits adjusting the strengths of poison columns during operation. This facility also provides additional transient and flux distribution control, permitting more efficient startups and better flattening at equilibrium operation. Other supplemental controls such as the Poison Spline Facility and the Displacement Column Facility are used to provide a complete and flexible control system for the Hanford reactors. Fringe enrichment is used to increase pile flattening while providing enough excess reactivity to maintain sufficient control rods in the reactor for adequate control.

25. Does the multiplication factor of a reactor change?

Answer: When a reactor operates at high level, its temperature rises because of the tremendous amount of fission energy released. From earlier discussions, we know that the higher temperatures inside the operating reactor will cause changes in the relationship among the fission, absorption, and scattering cross-sections for thermal neutrons of fuel and moderator. In addition, gas 
25. (Continued)

Answer: (Continued)

composition, fuel depletion, fission products, etc., will also cause changes in the reactivity status of the operating or shutdown pile.

26. Do all of these reactivity changes take place at the same rate? How are they controlled?

Answer: Some of the activities which cause these reactivity changes in the operating pile take place very slowly, and their effects are noticeable only over long periods of operation (long term variables). Others take place more or less rapidly (short term varlables). In order to keep the neutron activity at a constant level during these changes in pile reactivity, the pile operator must insert or withdraw control rod at such a rate that instrumentation trends indicating decreases or increases in neutron level are halted and the neutron level is held effectively constant at $k_{\text {eff }}=1.0000$.

27. What is meant by the term "transient"?

Answer: "Mransient" is a term used to describe the potentlal behavior of the reactivity in a pile under changing conditions such as fuel depletion, fission product poisoning, and temperature effects. Thus a "reactivity. transient" implies that the pile reactivity is not settled or established, but is shifting and changing continuously according to the pile conditions at any particular time. This variation in pile potential reactivity must be continually balanced by rod insertion or withdrawal.

28. What effect does fuel exposure have on pile reactivity?

Answer: As the reactor operates at high power levels, U235 atoms are consumed, causing a reduction in pile reactivity which proceeds at a rate proportional to the accumulated megawatt days of exposure. The amount of depletion or burnout which a reactor can tolerate depends on such things as the pile size, structure, slug concentration, and power level. If the maximum burnout of a high-power reactor is of the order of five to ten per cent, five to ten per cent more fissionable material must be loaded into the reactor to allow for fuel burnout. If a reactor were used to produce power only with no isotope production, it is easy to see how the fuel would deplete with time and lo se reactivity. In our reactor it becomes a little more complicated because the plutonium atoms formed during operation are also subject to fission; the net result is that the reactor does not lose reactivity nearly so fast and under some operating conditions may gain in reactivity.

29. What effect does the formation of plutonium have on pile reactivity?

Answer: Because plutonium-239 is highiy Iissionable by slow and resonance energy neutrons, the pile will gain reactivity from the formation of $\mathrm{Pu}^{239}$ in the operating pile. When fresh metal is loaded into a reactor,

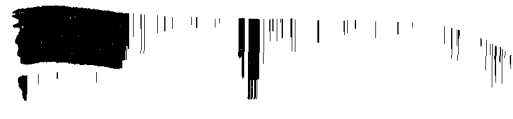


29. (Continued)

Answer: (Continued)

neptunium builds up to its steady state concentration and decays into plutonium with an effective 3.3 day lag. The neptunium and plutonium come into full equilibrium in a week or so according to tube power and pile exposure. The pile reactivity will then increase with time until the total effects of $U^{2} 35$ and plutonium burnout and fission product poison buildup begin to exceed that of plutonium formation; beyond this point the reactor loses reactivity.

30. Does the formation of plutonium atoms replace the UR35 burnout?

Answer: Not completely; although the plutonium buildup does not replace the U235 burnout atom for atom, it does provide an increase in reactivity because Pu239 yields more neutrons per fission than does U235 (about 2.89 to 2.43). $\mathrm{Pu}^{239}$ also has a larger fission cross-section than U235 (about 742 to 582 ). Above $600 \mathrm{MWD} /$ ton exposure, the burnout of both $U 235$ and $\mathrm{Pu} 239$ overcomes this effect, and the reactivity decreases with further exposure.

31. Dces the presence of samarium create any control problems in the Hanford reactor?

Answer: Although a potent absorber of neutrons, samarium is a minor problem compared with that of xenon poisoning. Promethium-149 is one of the fission products of $U 235$ and decays on a two-day half-life to samarium-149 which is a stable nuclide with a large absorption crosssection (66,000 barns) for thermal neutrons. As the samarium poison accumulates, the chance for burnout by neutron capture increases, so the pile reactivity absorbed by samarium reaches a maximum or saturated value of around $600 \mathrm{c}-\mathrm{mk}$ under steady operating conditions.

32. Which of the fission products is most important from the operating viewpoint?

Answer: The most important fission product to reactor operation is xenon-135 because of its large absorption cross-section - about $3.2 \times 10^{6}$ barns - for thermal neutrons. The effects of the xenon poison translents influence reactor operation in many ways. For example, although the saturated poison effect at equilibrium operation may cause a reactivity loss of 2 to $2-1 / 2 \% \mathrm{k}(2000-2500 \mathrm{c}-\mathrm{mk})$ in the usual power ranges, the decay of this amount of poison in the shutdown pile will represent a total swing of 4000 to $5000 \mathrm{c}-\mathrm{mk}$ from the initial xenon-free pile at startup. This delayed action effect in xenon formation and decay is the major cause for the scram transient, minimum downtime, and turnaround problems encountered in the operation of a high power reactor. A detalled discussion on the effects of xenon poisoning on pile reactivity may be found in Chapter IV of this series. 


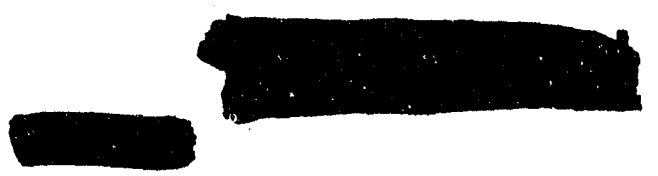

33. Does the metal effect cause a gain or loss in pile reactivity?

Answer: The metal temperature effect can cause gains or losses in pile reactivity of the order of 500 to $750 \mathrm{c}-\mathrm{mk}$, according to temperature change. The reactivity losses will occur through the heating of the uranium metal, the "gains" (actually cancellation of the losses) through the cooling of the metal. As the temperature of the metal rises, the increased absorption of neutrons by $U^{R 3} 8$ causes a loss in pile reactivity and produces a negative coefificient. Because the thermal conductivity of the metal is high and the thermal contact between the metal and water is good, the metal temperature follows the power output of the reactor with very little time lag.

34. Is there any connection between cooling water temperature and reactor power level?

Answer: The water temperature can directly affect the power level only through its inlet temperature which may fluctuate between $0^{\circ}-5^{\circ} \mathrm{C}$ during the winter to $20^{\circ}-25^{\circ} \mathrm{C}$ during the sumer. Thus, the inlet water temperature determines the delta temperature of a pile operating on set process or bulk outlet temperature limits.

35. Would a change in cooling water temperature have any effect on the pile reactivity?

Answer: The cooling water temperature has a twoway directional effect on both the graphite and metal temperatures. This occurs because an increase of water temperature must be accompanied by corresponding though somewhat smaller increases in the graphite and metal since it acts as a cooling agent for both materials. An increasing temperature will cause radial expansion of process tubes and slugs, changing the size of the water annulus and hence the amount of water present; the water itself expands and reduces the amount of neutron scattering and absorbing material in the annulus. Actually, increasing water temperature produces a "window" effect in the water annulus which tends to let "hotter" neutrons pass more freely between the metal and graphite and vice versa. Altogether, however, the temperature of the water itself is relatively unimportant in the reactivity status of Hanford reactors.

36. How does the water itself affect pile reactivity? Where is it accounted for?

Answer: The amount of cooling water and the power level will largely determine the temperature of the fuel elements, water, and graphite. The effect of the water 1 tself and its temperature are included in the reactivity calculations of the metal and graphite temperature coefficients.

37. Explain the connection between power level, graphite temperature, neutron energy, and graphite coefficient effect.

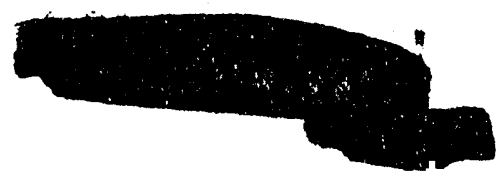


37. (Continued)

Answer: The power level determines the temperature of the graphite, and the graphite coefficient is directly related to the fact that the temperature or energy of the thermal neutron is set by the graphite temperature.

38. Using Figure 7, explain the relationship between graphite temperatures and pile reactivity.

Answer: As shown in Figure 7, the graphite temperature has a direct relationship with pile power and pile reactivity. In addition, the graphite temperature indirectly affects every other component or product contributing to the pile reactivity status. The main characteristics of graphite temperature changes are listed below:

(a) Graphite temperatures (assuming constant gas atmosphere) are directly related to power level.

(b) The temperature or energy of the thermal neutron is set by the graphite temperature.

(c) Higher graphite temperatures tend to increase the chance of plutonium fission; increased local plutonium fission results in a local increase in graphite temperature.

(d) The production of plutonium, samarium, and xenon are directly dependent on power level, but the graphite temperature also exerts a secondary effect on the production of each.

(e) Because the graphite temperature does not approach a steady state until an hour or more after a power change (or several hours after cold startup), the moderator temperature effect on pile reactivity is time sensitive to the heating and cooling rates of the graphite.

(f) Because of the thermal conductivity of the graphite and the gas composition, any change in gas atmosphere during operation will cause changes in the pile reactivity.

(g) As the graphite temperature changes, the various positive and negative effects cause associated changes in pile reactivity. The graphite temperature can cause gains or losses of two or three per cent in the neutron multiplication rate as the graphite temperature changes over a period of several hours.

39. What is meant by the term "reactivity transient" of a Hanford reactor? How are they controlled?

Answer: One might say that the "reactivity transient" is the net potential reactivity effect of a complicated combination of different components, isotopes and fission products, and temperature effects 
39. (Continued)

Answer: (Continued)

present in the reactor at any given time. Bach reactivity varlable has unique characteristics under varying pile conditions such as startups, turnaround, and steady state operation. Coolant flow, gas composition, rates of decay and burnout, fuel exposure and product formation are continuously changing in the operating pile. In order to control these reactivity transients, the reactor must be operated In such a way that the net reactivity effects can be handled within the capacity of the horizontal rod system plus supplementary control while operating, and by the addition of the safety rod system during shutdown outages.

40. Are reactivity transients considered a hazard to nuclear safety?

Answer: Only under certain non-staniard operating conditions. For example, an operating transient of five or more c-mk per minute is relatively fast, yet the operator can compensate 150 or more c-mk per minute if necessary. Thus nuclear safety is critical during full power operation only in the case of an accident such as flow stoppage or a gross operational error such as the sudden withdrawal of control rods. However, nuclear safety does depend on operational procedures and adequate instrumentation. For instance, it is very important that rod withdrawal rates (set by procedures) be conservative so that large excesses of reactivity cannot develop before a supercritical rate-ofrise can be measured by accurate instrumentation.

41. Does the pile reactivity ever reach a true equilibrium condition?

Answer: Not a true equilibrium; actually this is only an average condition over the pile as a whole. Small temperature and xenon changes are going on at all times, helped along by the frequent rod movements and by self-induced reactivity effects of these transients themselves. As each minor change occurs in various sections of the plle, control rod is inserted or withdrawn to maintain a constant reactivity $\left(k_{\text {eff }}=1.0000\right)$ and thus a constant power level.

42. Could a reactivity event in the "controlled" pile proceed to an extent as to cause a lapse of control, or a power exursion?

Answer: There are three common occasions in which this could occur: (1) lack of sufficlent control at turnaround, (2) lapse of control while operating, especially during poison discharge or spline work, and (3) excessive and continued rates of rise during reactor startup. Excursion possibilities due to loss of cooling water would also be potentially serlous, but cooling water supply is not under the direct control of the reactor operator. 


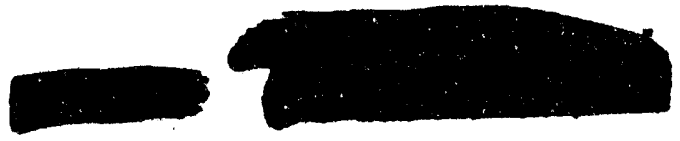

43. What determines the size or magnitude of the reactivity transient after a cold startup?

Answer: The magnitude of the reactivity transient from startup to turnaround will depend primarily on the power level, the amounts of lodine and xenon present, and the metal and graphlte coefficlents. Thus, the startup level and operating efficiency will be limited by the amount of rod available for controlling the reactivity transient following startup. A particular power level is determined through calculational methods such that the resulting transient will barely not exceed the capacity of the control rod system.

44. From information shown in Figure 9, give the following: (a) inhours (and $c-m k$ ) In rod at time of scram, (b) reactivity gain or loss immediately following scram, (c) inhours (and c-mk) in rods at time of scram recovery, (d) time from scram to equilibrium condition in the recovery case, (e) time and amount of minimum reactivity, ( $f$ ) minimum downtime, ( $B$ ) inhours (and c-mk) in rod at turnaround, and $(h)$ time from cold startup to equilibrium conditions.

Answer: (a) 400 inhours, 1000 c-mk; (b) about 200 inhours, 500 c-mk, reactivity gain from metal cooling; (c) about 175 inhours, 438 c-mk;

(d) near-equilibrium conditions in about 6 hours; (e) reactivity loss of more than 1000 inhours (2500 c-mk) about 10 hours after scram;

(f) about 28 hours; (g) about 800 inhours, 2000 c-mk; (h) about 48 hours.

45. Would running out of rod at turnaround be considered a nuclear safety hazard at Hanford?

Answer: The possibility of a power excursion resulting from lack of control at turnaround is considered as an operating problem rather than a safety problem. In normal reactor operation it is extremely unlikely that a transient as fast as one inhour per minute $(2.5 \mathrm{c}-\mathrm{mk} / \mathrm{min})$ would occur at turnaround after running out of control rod. Such fast rod movement just prior to turnaround would surely be noticed and remedial action taken before actually running out of rod. However, assuming that the reactor would gain reactivity at the rate of $2.5 \mathrm{c}-\mathrm{mk}$ per minute, the power level would increase two per cent in the first five minutes. Under these circumstances, plenty of time would be available for operator action (manual scram of the VSR's) some time before emergency trips would take place.

46. Would the accidental discharge of a full column of poison during reactor operation cause a power excursion? What precautions are taken?

Answer: The discharging of poison columns during reactor operation is normally covered by procedures requiring prior insertion of control rod and reduction of power level. Should this procedure break down and a poison column be flushed rather than displaced plece by piece, a total power rise of approximately six per cent would occur within about 30 seconds. At this time the power rise would be limited by the negative metal coefficient which had taken place. The slow rate of power rise would afford plenty of opportunity for an automatic trip should any 
46. (Continued)

Answer: (Continued)

tubes approach instablilty. Iimits before the operator had taken compensating control action. However, local tube limits based on rupture considerations could be exceeded, especially because of the sudden increase in local flux. Protection against such excursions and sudden hot spots which could lead to rupture rashes may be provided by procedure - by cutting power level and local tube limits during poison column discharge, and by zone temperature monitoring with careful attention to light and alarm indications.

47. Why are rod withdrawal rates restricted during a cold startup?

Answer: The phase of operation most pertinent to reactor safety is the startup, where extremely fast rod withdrawal rates could cause an excessive rate of rise. Large changes in reactivity can take place during a minimum or extended outage, especially in case of gross loading errors; so there is always a chance for error in the calculations for critical. For this reason a conservative rate of rod withdrawal is the only safe method of approaching critical, and controlling the rate of rise is the only safe method of reaching the desired operating levels. Of course, as one's knowledge of level and period is improved through better instrumentation, a faster withdrawal rate may be as conservative as the slower rate was without good instrumentation.

48. Are rod withdrawal rates equally restrictive for "hot" startups?

Answer: No, during a hot startup more liberal withdrawal rates are allowed. In this case, the pile reactivity is rapidly falling away in a "failsafe" direction. It is falling so fast that allowances must be made for its rate if the scram recovery is to be accomplished. Here the pile conditions are safer; the falling transient values are better known and there is no reasonable chance of unknown loading or poison changes to take place. Therefore, a somewhat faster rate of approach to critical is permitted in the hot startup case.

49. Should a reactor operator depend on automatic safety controls?

Answer: No, the operator's main task is to keep the reactor under complete manual control at all times. He should consider the automatic safety trip backup in the same manner as an automobile driver considers emergency brakes, seat belts, and dashboard padding.

50. What are the four main functions of a reactor operator with regard to reactor control?

Answer: The flexibility and variety of responses required to adequately control the pile under varying conditions makes it difficult to describe the exact duties of the plle operator. In general, the main functions 
50. (Continued)

Answer: (Continued)

may be defined as: (1) to accept and analyze instrument data, (2) to correlate pertinent information, (3) to make prompt decisions, and (4) to exert the appropriate control action.

51. Explain the relationship between operator reaction time and automatic safety devices.

Answer: During emergency operating conditions the reaction time of the operator sets a definite limit upon the speed with which he can accept information, formulate a decision, and take corrective action. For example, if an instrument indicates that the neutron flux is rising at a dangerously fast rate (10-second period or less), an operator may not be able to act quickly enough to decrease the reactivity in time to avold an accident. In circumstances of this kind, it is far better to automatically insert control rods than to rely entirely on human control. In order to ensure safe reactor operation, operating standards and procedures are set for operator guldance and enforcement which, if followed exactly, should always keep conditions within the reaction time of the operator; automatic devices are then provided as a second backup to cover the possibility of procedural breakdown or operational error.

52. Why is a production reactor always made somewhat larger than the exact critical size?

Answer: When a production reactor is started with a fresh loading of "green" metal the polsoning of the chain reaction by fission products formed, and other short term and long term reactivity contributions and losses, must be compensated for in order that the reactor can continue to operate at a constant rate as these changes take place. For this reason it is necessary that the reactor be made larger than critical size and use some neutron absorbing material which can be introduced into the reactor in controllable amounts. This excess reactivity. allows leeway against the self-polsoning tendency of the chain reaction and against any temperature effects on the multiplication factor.

53. What is the approximate amount of excess reactivity built into a Hanford reactor?

Answer: The size of the reactor is so much larger in excess of that actually required for the chain reaction process that a considerable amount of absorbent material must be used to bring the reactor to the point of steady operation. The amount of excess may be of: the order of $2-1 / 2 \% \mathrm{k}(2500 \mathrm{c}-\mathrm{mk})$, most of which can be compesulatied by the hor 1zontal rod system. 
54. If the amount of excess reactivity built into the pile is greater than the capacity of the horizontal rod system, how then can it be controlled?

Answer: During reactor shutdown the vertical safety rod system is added to the horlzontal rods to hold the plle subcritical. During reactor operation small changes in temperature, coolant flow, and reactivity variables cause positive or negative reactivity effects to take place from minute to minute. These small reactivity changes are compensated by moving a small amount of the horizontal rod system in or out of the reactor as these changes take place.

55. What is the principal difference between operating control and safety control?

Answer: Operating control would include the use of sufficlent poison to control the reaction during startup, normal transients, and equilibrium operation. In case something unexpected should occur during operation which resulted in a sudden large increase in the multiplication factor, a loss, in coolant supply, or some other threat to the reactor, it would be necessary to insert quickly a large additional amount of polson material into the pile. The fast insertion of large amounts of poison materlal is known as "safety control." The operating control system must be flexible enough to allow adjustment of neutron flux during all conditions of operation; the safety control system must provide a "fail safe" component which is automatically activated under emergency conditions.

56. How many control systems are used at Hanford? What is the function of each?

Answer: Control requirements at Hanford consist of a combination of three independent systems: (1) the horizontal control rods (HCR's), (2) the vertical safety rods (VSR's), and (3) the Ball $3 \mathrm{X}$ system. The HCR's, supplemented by PCCF columns, splines or other operating control devices, provide sufficlent polsoning effect to control the reaction under normal transient and equilibrium operation. The VSR's have sufficient strength to hold the "wet" pile subcritical even after complete xenon decay and provide the rapld shutdown capablilty required. The Ball $3 \mathrm{X}$ system is designed to independently hold the dry, xenon-free pile subcritical.

57. What is most likely to limit the total output of a production reactor?

Answer: A production reactor's "weakest link" will probably be the heat generation rate of some particular component at only one part of the reactor. If most of the volume of the reactor can operate at heat generation rates approaching this limiting rate, the total output w1ll be much greater than if temperatures fall off isharply in all directions from the limiting component. Because it is not always possible to have everything symetrical within the reactor it is necessary to develope techniques for maintaining a balanced heat distribution in spite of non-symetric loading and control rod patterns. 
58. What is the "flattening" concept?

Answer: In order to achleve a critical size pile, it is necessary to have a lattice design with a $\mathrm{k}$ infinity greater than one. This means that each small increment of volume inside the pile is producing neutrons faster than It absorbs them and these excess neutrons leak toward the sides of the plle where they escape. Since the lattice cells near the edges of the pile can send their excess neutrons in any dirction, toward the center as well as toward the edges, the neutrons will tend to peak or pile up in the midale of the pile. In a supercritical plle, enough neutrons could not leak out the sides to prevent a continuous bulldup of excess neutrons in the middle of the pile - an uncontrolled reaction. By placing the right amount of control rods or other poison material at just the right spacing in the middle, the central leakage to this poison will just balance the excess neutron production. The effect of this arrangement is the same as having a central. region with $a k$. Infinity of one, and the side region with $a k$ infinity sufficlently greater than one to make up the neutron leakage out the sides. By this method, the pile neutron distribution can be made "flat" to some degree.

59. What is meant by "temperature moment"?

Answer: There is a direct relationshlp between heat generation and neutron production rate. Although we measure temperature effects, we are actually getting an indication of local fission rates, or more basically, local neutron population. If the neutron population per unit volume is greater in one portion of the pile than in another portion symetric to the first, it means that this second region has greater chain-reacting tendencies than the first. This difference in chain-reacting properties, or local reactivity effects, can be caused by the local presence or absence of a control rod tip, by local temperature or fission product poison effects, or by local differences in loading patterns. The trick to getting heat generation rates symetrical over the pile is therefore that of balancing the reactivity properties of symetrical reglons about the pile. If control rods are only partially inserted on the near side of the pile, an equal amount of rod or some other polson materlal should be added to the far side of the pile to balance the reactivity effects. "Or if the pile has been operated for a considerable length of time with a skewed distriblition so that fission polsons have bullt up more strongly in the top half, an unbalance in the control rod pattern toward the bottom half of the plle must be made to achieve symetrical regions of equivalent reactivity properties.

The unbalance of reactivity properties in symetrical regions about the pile is proportional to the amount of reactivity and to the spacing of the unbalanced regions. The effect is quite simflar to a teetertotter; the unbalance is proportional both to the welght of the 
59. (Continued)

Answer: (Continued)

Individual and to his distance from the center of the board. The product of the weight and "lever arm" in the teeter-totter case is known as a moment of force in mechanics; the concept is useful to us in thinking of measuring temperature unbalance as a "temperature moment." Thus, the farther a control rod is from the center of the reactor, the greater "temperature moment" or unbalance it will cause. And the greater the size of the increment of poison, the greater will be 1 ts "temperature moment."

60. Assuming an 1deal neutron distribution throughout the reactor core, describe a "temperature moment" created by control rod movement.

Answer: If a certain omount of control rod is inserted at one point in the reactor and the total power level is held constant by the uniform withdrawal of all other rods, the neutron flux or local power will tend to decrease at the point of rod insertion and increase in all other regions of the cube. However, the poison effect of the inserted control rod is not strictly localized, but rather exerts an over-all effect which diminishes as the distance from point of insertion increases. Thus, the least polsoning effect would be experienced in the region farthest from the point of insertion, and the flux would have the greatest tendency to increase in that particular area. The region of maximum increase can be expected to occur diametrically across the center of the cube at a point which is approximately the same distance from the center of the pile as the point of rod insertion. An analogy which may be useful to obtain a mental picture of this situation is to consider the total flux or tube power distribution as an Inflated membrane attached to the edges of the tube temperature map. As you insert control rod in one region; that is, press down on the membrane at one point, it tends to bulge upward in a region across the center point from the depressed region.

61. Which type of control is important - heat distribution or total power?

Answer: Both are equally important; we know that control rod movement is required during operation to control temperature and fission poison effects, and that this rod movement causes changes to occur in different reglons of the reactor which may make these regions unbalanced in reactivity properties. If we control solely to maintain the overall reactivity constant (constant power level) we may initiate distortions in the temperature distribution about the pile. Actually, we must control both for constant over-all pile power level and for balanced temperature distribution. 
62. How can an operator know what is happening to the reactivity properties of each little increment of pile volume at any given time?

Answer: This approach would be much too complicated. We can get a better Idea and a better feel for what's golng on simply by watching the instruments which tell us temperatures and neutron population at different points about the pile and how they vary with time. Going back to the teeter-totter 1dea, we need to be able to add welght to e1ther side if it starts to get out of balance in order to get it back in balance again. We can keep the total weights (constant power level) by lightening one slde slightly by the same amount which is added to the other. In case of temperature distribution problems, we need to be able to insert some control rod into the region which is getting too hot and simultaneously be able to withdraw some from the region which is getting too cold. The best approach to solving the temperature distribution situation is to divide the problem into two parts:

(a) General degree of flattening - this is generally taken care of in advance by recommended rod configurations and loading changes.

(b) "Moment" control - by thinking in terms of trends in the three dimensions of space (vertical, sideways, and lengthways) instead of point by point throughout the reactor.

In reactor terms, the trends in the three dimensions of space become near-to-far, top-to-bottom, front-to-rear. The operator can control the temperature better through directional trends than he can by following point to point indications. So long as he can keep the temperature "moments" in good balance and the hottest spot in the reactor within limits, he doesn't have to worry about so many detailed data points.

\section{What is the "small piles" control concept?}

Answer: The "small piles" concept is a method of visualizing the entire reactor as being made up of, say, elght blocks or cubes of equal size, each of which must be controlled to operate smoothly at optlmum power level. Four of these small piles would then be to the rear of reactor center and four to the front, four above center and four below center, etc. This is merely a method which may help us to think in three dimensions when selecting control rods for even flux distribution over the ent1re reactor.

64. Can each of these elght small piles be controlled separately?

Answer: Not entirely; in order to establish control over each of these small plles, one or more rod tips must be placed in each region so that movement of the rods will affect the flux density and tube temperatures in that region. Although each small pile may be considered separately, one must remember also that a change of flux and the 
64. (Continued)

Answer: (Continued)

resulting transient is not confined to each small region, but will in turn induce similar changes in adjacent reglons. Thls effect gradually diminishes as the distance from the first region increases.

65. What type of operating transients can be expected in each of these smail piles?

Answer: The primary transients created by rod manipulations are metal heating or cooling, graphite heating or cooling, and xenon buildup or burnout.

66. What effect does metal heating and cooling have on fiux and power?

Answer: Adding or subtracting an increment of poison by control rod adjustment results in absorbing more or less neutrons from the region of interest, and causes an increase or decrease in the local flux and power in that particular region. Because the metal coefficlent has a negative effect on pile reactivity it will tend to counteract any change in the local power or reactivity caused by the rod movement. Therefore, any change in the small pile region is stopped almost instantaneously by the metal coefificlent. The net result is that the local power level changes from just critical at one level to just critical at a different power level. However, this is just the metal effect; two other timedependent temperature transients quickly begin to change this simple just-critical condition.

67. Once a flux or power change is made in a given region of the pile, does the flux remain constant until another rod adjustment is made?

Answer: No, because the flux change is merely the first event of a serles of reactivity changes. For example, when flux is increased the positive graphlte temperature coefficlent acts in the same direction as the increased rate of xenon burnout, thus increasing or strengthening the gain in reactivity. This tendency must be counteracted by rod insertion in order to maintain the desired flux distribution. The reverse condition acts in the same manner; when the flux is decreased, the buildup of xenon and the graphite cooling result in a decreasing reactivity trend. This tendency must also be compensated by control rod withdrawal from the region to maintain constant power. Furthermore, the above reactions are those seen immediately of ter a flux change; several hours later the transient effect inltiates a flux change in the opposite direction.

68. If a certain amount of control rod is inserted into one of the small pile regions to reduce the $f l u x$, will the withdrawal of an equal amount of rod during the resulting transient compensate fully for the reactivity change? 
68. (Continued)

Answer: Not fully, only in part. Because the combined reactivity effects of changes in graphite temperatures and xenon bulldup are usually much larger than the reactivity gain from the metal temperature effects, much more rod must bn withdrawn temporarlly than was originally inserted to cause the reduction in flux. The reverse condition (withdrawal of rod) also will act in the same manner.

69. Do these reactivity translents take place every time a small control rod adjustment is made?

Answer: Yes, when a small amount of control rod (rod t1p) is inserted into a "small pile" section to reduce the local flux, the following sequence of events occurs: When one rod 1s inserted and other rods are pulled to compensate, the power and flux level in the problem region drops, then the decrease in the negative metal coefflcient effect temporarily stops the flux from falling farther. After the local flux change, local xenon bulldup is greater than burnout-plus-decay, resulting in a loss of reactivity; the graphite 0180 begins to cool to a lower temperature value and another reactivity $108 s$ results. If rod is not withdrawn from this region, the reactivity loss will continue and pick up speed. If rod is withdrawn from this area to maintain the local power level, the xenon transient will reach a "turnaround" in four to elght hours where xenon decay and burnout equal, and then exceed xenon bulldup. From this point the xenon decreases to its new saturation value. While these translents occur in one "small pile" region of the reactor, opposite transients must be occurring in other regions whert rods were pulled and flux increased. More rod movement is required to control the resultant turnaround of these non-symetrical transients during the same four to elght hour interval.

70. What would occur if these "small pile" reactivity transients were not controlled?

Answer: A serles of these local transients and changing power levels taking place in opposite sections of the reactor will cause certain sections of the pile to vary with time in both reactivity and heat generation properties. Changes in graphite temperatures start reactivity effects which cause the process tube outlet temperatures to osc1llate; when the tube temperatures oscillate beyond limits and force a power cut, subsequent control rod movement adds to the cycling tendencles. These flux drifts from one section of the pile to another are known as "temperature cycling" and have perlods ranging from 12 to 36 hours.

71. How important is the selection of the proper rod for control during equilibrium conditions? 
71. (Continued)

Answer: Very important - The effects of loss of control vary in seriousness depending on the strength of the transient (which varies with time) and the size and location of the region in which control is lost. For example, assume that the reactor is at equilibrium and that the near-top-rear "small pile" section is high in flux and tube power. If an error were made and the wrong control rod used, a front top near rod might be inserted into a relatively baianced flux region which would instantly create an additional problem area. Thus the selection of the wrong control rod can strengthen existing transients and create new ones; the continuing reactivity transients then cause further changes in local power and flux. Should these transients be permitted to proceed until all avallable control rods are withdrawn from regions which are still decreasing in reactivity, the process then "snowballs" unless other means are found to reverse the reactivity trend.

72. If control flexibllity is lost in one region of the pile because of rod withdrawal, what other means of control are available?

Answer: Referring to the small pile concept, if the control is lost in one of these small pile sections, it is sometimes possible to increase the over-all pile reactivity by increasing graphite temperatures with $\mathrm{CO}_{2}$ additions. By inserting control rods in the other seven small pile regions, the relative flux should increase in the problem area, thus reversing the reactivity trend.

In addition to gas composition changes, PCCF tubes and poison splines are used to reduce the magnitude of flux cycling in one or more reglons of the reactor, thereby making available more control rod for more flexible control. A new supplementary control system; the Displacement Column, is expected to provide adequate front-to-rear control over flux cycling tendencies. This system consists of a fuel column with poison pieces replacing fuel elements at each end of the column. By means of a remotely controlled winch and cable arrangement the entire metal column may be moved upstream or downstream within the process tube, thereby inserting poison at one end of the tube and simultaneously withdrawing it at the other end. Correctly positioned about the reactor, ten or twelve displacement columns shoula provide direct control over front-to-rear cycling conditions.

73. What happens if undesirable reactivity trends cannot be reversed?

Answer: Any change in flux w1ll "snowball" if permitted to proceed, and the longer it is ieft uncorrected the more rod is required to correct 1 t. If allowed to continue the loss of control will become more general, as when it is lost on the entire near side of the reactor under a condition of falling reactivity. When all near side rods are withdrawn,

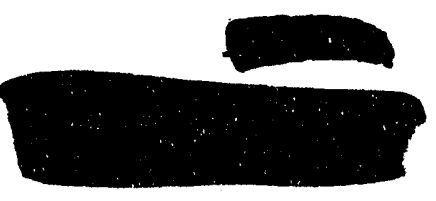


73. (Continued)

\section{Answer: (Continued)}

the flux usually continues to decrease on the near side and increase on the far side. Under these conditions, withdrawal of rod from the far side will force a cut in power because of far side rising tube outlet temperatures.

74. If near side control were lost (all near side rods withdrawn), would a cut in power level solve the problem?

Answer: When an unbalanced flux distribution reaches this stage, rising process tube temperatures force a cut in power level in order to remain within specified temperature ilmits. The power cut does not relleve the temperature or distribution problems since a cut in power causes even faster xenon bulldup and graphite cooling, requiring further rod withdrawel. Since the only remaining rods are long rods inserted to the far side, pulling these rods may only accentuate the flux distortion and lead to further cuts in power until the reactor is shut down.

75. Can the speed or direction of required control rod movement be altered in any way during reactor operation?

Answer: Yes, the speed or direction can be changed through the graphite temperature contribution by varying the gas atmosphere composition. Increasing the helium concentration of the gas allows the graphite to cool, the reactivity contribution decreases, and rods must be withdrawn to compensate. Increasing the $\mathrm{CO}_{2}$ concentration slows or hampers the graphite cooling, the reactivity contribution increases, and rods must be inserted to maintain constant power. This procedure must remain within the graphite temperature limits as specified by Process Standards.

Supplementary control systems such as PCCF columns or splines may also be used to augment HCR control flexibility.

76. Name three pile conditions where gas composition control might prove useful.

Answer: Control by variable gas composition could be useful under the following conditions:

(a) Many times during reactor operation it may be desirable to insert rod tips into a high flux region or withdraw rod tips from a low flux region without compensating by rod movement in other regions of the reactor. When controlling by this method, the flux distribution change can be accomplished in a smooth and gradual manner through the selection of the correct rod for minute-to-minute

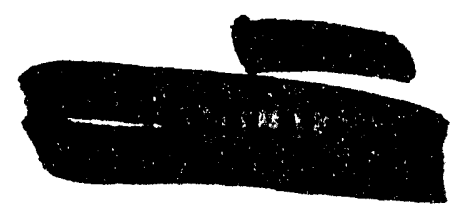


76. (Continued)

Answer: (Continued).

(a) (Continued)

control, thus avolding the many small transients whlch occur when a number of rods are adjusted to correct the flux distribution.

(b) When the reactor is experlencing long term reactivity gains due to plutonium buildup, this gain in reactivity must be compensated by rod insertion to maintain the desired level. In many cases, the omount of rod in the reactor increases to the point where further rod insertion may result in loss of a flexible configuration, and flux distribution and temperature control would become troublesome. This condition can be avolded by adding helium to the gas atmosphere at a controlled rate so that the reactivity held In the HCR's remains the same or is allowed to increase at a slower and more controllable rate for optimum flattening.

(c) When a high helium concentration is maintained during equilibrium operation, a $\mathrm{CO}_{2}$ purge when the reactor scrams is sometimes used to reduce the rate of graphite cooling while the reactor is down to provide extra reactivity for a recovery attempt.

77. Are the Hanford reactors equipped with instrumentation specifically designed to provide operational control information?

Answer: Untortunately, most of the control instrumentation was originally designed before the techniques for flux distribution control were developed. Consequently they were designed primarily as a means of observing operating limits, or as a protective system, rather than to provide control information. Consequently, the readings from such instruments as the tube outlet temperature monitors, Beckman flux monitors, octant monitors, graphite temperature thermocouples, and power level recorders must be adapted to provide the information necessary for adequate control. Readings from all informative instrumentation must be combined mentally into a three-dimensional picture of flux distribution, and control rods manipulated in such a manner as to counteract any changes in order to maintain or improve the flux distribution.

78. Once established, does the relationship between the various instruments remain constant?

Answer: Yes, for a given operating period only. For maximim control benefit, all instrumentation should be checked for sensitivity and calibration for each new equilibrium operating perlod. Since the previous flux distribution may. be distorted by discharge of poison, enrichment, or high exposure metal, instrument settings may not coincide with the 
78. (Continued)

Answer: (Continued)

new pile condition. After the reactor reaches an equilibrium condition following a discharge outage, every effort should be made to determine whether any instrument requires adjustment to improve and maintain an even flux distribution. In other words, good pile control does not depend on a single indication from any one instrument. Any reading which appears out of line should be carefully checked against all other avallable information before any control declsions are made.

79. What is the connection between startup power level and the magnitude of the following reactivity transient?

Answer: The three major startup transients, the negative metal reactivity effect, positive graphite reactivity contribution, and the xenon buildup and burnout changes are all dependent on the startup power level. At the higher operating levels, the large xenon burnout following a minimum outage limits the startup power level to a point where it becomes uneconomical to start up unless temporary poison, poison splines, or some form of additional poison is used to supplement the HCR system. When all the HCR's are inserted to override the startup transients, the region within the rod pattern is overpolsoned, and the regions outside the pattern become the areas of high flux and high tube temperatures. Since an operating limit is placed on the maximum tube power or outlet temperature, the amount of this flux and temperature distortion partially determines the startup power level.

80. How important is flux flattening just prior to or imediately after "turnaround"?

Answer: During the approach to turnaround individual rods are selected for insertion so as to maintain the best possible flux distribution in order to avold local high flux regions and limiting tube temperatures. When a low flux level is allowed to persist in any. particular region of the reactor, other sections of the pile are essentially operating at a higher power level. This equivalent power level may be high enough so that the local transients eventualiy exceed the local poison effect, and a loss of control is experienced in this section of the pile. If this occurs, further flux distortion may take place, again strengthening the existing transient, and the process may "snowball" until power cut, and possibly eventually a shutdown, is required to avoid exceeding the operating limits. 
81. Why is a knowledge of previous operating conditions important?

Answer: Some of the reactivity changes occurring in an operating pl.le have fairly long time constants. For example, the typical cycilng problem is associated with the haif-IIves of xenon and lodine ( 9 and 6 hours, respectively) and with the graphite heating and cooling periods. Consequently, the translents build up and die down over a period of about one day. To damp out and control such a cycle it is necessary to know what the trends are at a given time and what the operating hlstory has been so that one can anticlpate and counter future flux changes. For these reasons, an accurate history of reactor operation for the preceding 24 hours should be avallable at all times during operation.

82. How should control rods be withdrawn after turnaround? Explain.

Answer: After turnaround the reactivity starts to decrease due to xenon buliding up faster than it is burned out and decays. As the reactivity decreases, power level is ralsed and this causes the reactivity to decrease at a slower rate because of the higher xenon burnout and Increased contribution from the graphite heating.

As the pile reactivity decreases, the sequence with which the control rods are withdrawn will determine the flux distribution about the reactor. In other words, the sequence is set up so that the remaining inserted rods will balance the flux distribution in all sections of the pile. A pattern should be set up and followed such that there is always an avallable rod tip in each of the "small pile" control regions of the reactor. This flexible rod pattern should be obtained as soon as possible after turnaround so that the transients set up in various parts of the pile by the power raises will tend to further maintain an even flux distribution. Elimination of the need for large distribution corrections after turnaround tends to make a smoother, more efficlent approach to an équilibrium operating level.

83. Does the amount of reactivity held in the rods impose any IImitations on the approach to final operating level?

Answer: Yes, the approach to maximu operating level must be made cautiously because xenon poisoning will continue to increase as a result of the final raise in power level. This will require rad withdrawal to compensate for the xenon increase; if the power level is too high, extensive rod withdrawal may cause tube outlet or graphite temperatures to be exceeded. By slowing the power ralses as limits are approached, the equilibrium power level is reached at approximately the same time as the equilibrium reactivity. Final adjustment of control rods, power level, flux and temperature distribution can then be made to approach a maximum power level without forced changes in rod configuration. 
84. If flux changes take place every time a control rod 18 moved, how can temperature cycling be prevented?

Answer: Since temperature distortion is usualiy the result of a series of local power changes in certain parts of the pile, the only way to prevent severe temperature cycling is to malntaln a teady flux distribution over all sections of the reactor. Bven flux and temperature distribution can be maintained only through the correct interpretation of representative monitoring data taken at frequent time intervals. Good control rod techniques are then necessary to correct any detrimental flux or temperature trends before they become too difficult to handle. Assuming a basic understanding of the "temperature moment" and "small pile control" concepts, the problem becomes that of selecting the proper control rod for given local trends:.

85. Can multiple-point recorders, such as tube temperature deviation and graphite temperature, be relied upon completely?

Answer: No, temperature maps and individual tube outlet temperature read-out are considered as the final authority and what the absolute flux distribution is and what the tube temperatures are. Supplemental instruments such as the corn popper, zone temperature monitor, and tube temperature deviation recorders are designed to provide crude data on temperature stablilty or trends. Since most supplemental instrumentation can be adjusted or blased to fit a particular operating period, this type of equipment cannot be relied upon until adjustment is made for existing pile conditions. In other words, strict adherence to a single false or blased indication from any one instrument can lead to severe control difficulties.

Becaise of the relatively slow graphlte heating and cooling periods, one cr more couples on the graphite temperature recorder may increase or decrease over a period of time before emerging from the stripchart "field" as a potential threat to flux stability. This occurs on all multiple type recorders and results in a tendency to ignore small changes until the transient becomes more or less firmly established.

86. Can a true picture of temperature and flux distribution be obtained so that misleading or false indications can be recognized?

Answer: Yes, the first step is to obtain a picture of existing tube outlet temperatures in representative sections of the pile. A fast and simple procedure for tube temperature sampling such as the following can be set up to obtain comparative readings in a minimum of time. Nine tubes, carefully selected, can be monitored quickly for tube outlet temperature through the use of the skip-switch or hand jack. Tube location should be carefully chosen so that individual tubes are evenly spaced about the flattened zone and are not unduly influenced by venturl size (flow), adjacent enrichment, polson, etc. Four tubes, each located the same distance from the edges and/or the center of the reactor, will monitor the temperature of each of the four main sections of the pile. 
86. (Continued)

Answer: (Continued)

W1th an even flux distribution, each of the corner tubes should operate at approximately the same tube temperature. The temperature of each quadrant can then be compared with the temperature of all other quadrants. In addition to the four quadrant tubes, three tubes can be selected across the center of the plle to manitor this area. For overall top and bottom control, one tube is placed at top center above the rod pattern, and another at center bottom below the rod pattern.

Repeated readings of these tubes recorded on a work sheet over a period of hours will show definite trends resulting from previous operation as well as existing conditions. In this way a clear plcture of the rate and extent of the flux and temperature trends w11I provide accurate data for comparison with instrument performance. After an even temperature balance is obtained by the temperature ampling method, outlet tube temperature points can be accurately adjusted on the deviation recorder to maintain or improve the flux distribution.

87. Does the outlet tube temperature map present a clear plcture of flux and temperature distribution?

Answer: The temperature map (or any tube temperature monitor) w1ll quickly Identify the regions of high and low temperatures in the four main sections of the pile, but (1) It cannot supply information on front-torear elux distribution or temperature, and (2) a single map does not show changes, and it 18 difficult to define specific trends from the mass of data on a number of maps. Thus, the tube outlet temperature map represents only the first step in determining the flux distribution; further information is necessary before any control action can be made.

88. What information is necessary in order to take any control action?

Answer: Before an intelligent decision can be made, consideration must be given to the "small pile" control concept. Recalling the mental image of the entire reactor as beling composed of elght small piles of equal size, and knowing that control rod movement will inftiate reactivity and temperature changes according to the prevlous operating history of that particular region, further information is required to justify the use of any particular control rod. In other words, each of the elght small plles is primarily controlled by one rod tip only; the selection of the wrong rod will create a transient in Its own. locale, and have little or no effect on the region of interest. For an even flux distribution each of the elght small piles should contribute equal amounts of flux density or power; therefore, a comparison of temperature indicating flux density, must be made to determine the control action to be taken in each of the elght sections. A comparative pleture of the flux distribution in each of these elght small piles, especially in the front-torear direction, can be obtained from a graphite temperatura survey.

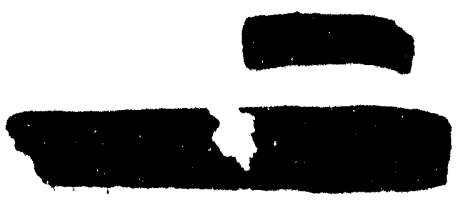


89. What type of instrumentation w1ll give front-to-rear flux 1nformation?

Answer: At the present time, eraphlte thermocouples are the only reliable source of front-to rear flux density information in the older reactors whlch can be used to determine whether front or rear control rod hould be used. Thermocouple locations hould be slected to colnclde w1th the outlet tube temperature sampling pattern and arranged on a work sheet for quick andysis of front-to-rear temperature distribution. For example, the tube outlet temperature may indicate that rod w1thdrawal might be made in the top-near section of the p1le. Th1s area Includes two of the mall plles, front and rear. From which mall pile should the rod be withdrawn? Careful nalysis of the repaphte temperature pattern reveals that the top-near-front temperature is considerably less than other comparable front thermocouples about the reactor, whereas the temperature of the top-near-rear is among the highest in the entire reactor. Obviously, any rod removal from this region should be from the front small pile. Removal of rod from the rear small pile would Increase temperatures in a high flux area, eventually resulting in a so-called "temperature cycle."

90. Why should tube outlet and graphite temperature be taken on work sheets when graphite temperatures are chart recorded and tube temperatures are given on a multiple-point recorder?

Answer: First of all, tube outlet and graphite temperature sampling patterns used over a period of hours will show definite temperature trends as well as existing conditions. Continual analysis of this type of information will quickly develop a three-dimensional picture of the ent1re control problem. Plle conditions can change from outage to outage thereby changing the value of certain instrument readings. Instruments can be blased or adjusted to fit the preceding operating perlod and should not be relled upon until double-checked against existing pile conditions. Because most instrumentation provides only crude information, there is a tendency to 1 gnore small changes unt1l the transient becomes firmly established. These small changes can be easily followed on temperature sampling patterns; the results of rod adjustment can be monitored to one-tenth of one degree of tube temperature and to one degree of the slower-changing oraphite temperature. Repeated sompling in the same pattern of these two all-important control factors, taken at regular time Intervals, soon presents a mental image of all reactivity changes occurring in the pile and provides a complete history of past perform.. ance and flux distribution.

91. Some reactors are equipped with octant monltoring systems. When 18 this system useful?

Answer: The usefuliness of the octant system or any other monitoring device can only be measured by the experience and resourcefulness of the people using the data. The octant system measures and records the neutron flux at each of the elght corners of the reactor; although it was 
91. (Cont1nued)

Answer: (Cont1nued)

Installed primarily as a safety device, comparison of the Individual readinge can be used for high level distribution control in many ways. For alven power level, ang change of neution flux in one of the - Ight regions (amall p1les) must be balanced by a correeponding change in sane other region (mechanical moment analogy). When used in conJunction with tube and graphite temperature data, each octant meter reading can be used as additional confirmation of a suspected flux situation and/or to provide a clue as to whether the desired results are belng obtained from previous rod adjustments made to improve the Ilux or temperature distribution. The octant chembers are useful during a cold startup to plapoint the correct "small pile" region for rod insertion at a time when all other pile date 18 at a minimum. At operating levels each octant provides a clue as to when to take corrective action and what method to use, and $\mathbf{w 1 1}$ then record the success or fallure of the action taken. Octant data can be verifled with tube outlet and graphite information, thereby providing a means of doublechecking the temperature trends as they develop in varlous regions of the reactor.

92. Can Becloman readings be used for control purposes?

Answer: Although primarily designed for flux level monltoring, the chembers can be used to detect silght flux changes in the lower portions of the plie. In addition to top-to-bottam control, a knowledge of individual chamber location provides another means of detecting flux and temperature trends in the lower sectlons of the pile. Th1s information, coupled with octant monitoring, tube outlet, and graphlte data provides an additional method of double-checking the flux and temperature trends In the ent1re reactor.

On the other hand, Beckman readings can be very misleading if not used in conjunction with other 1ndications. For example, alling Beckman reading might be interpreted as "safe," whereas an undetected distortion to the top might be its real signiflcance.

93. Can perfect equilibrium conditions be maintained in the ganford reactor?

Answer: The control of a Hanford reactor 18 a never-ending task in the sense that perfect flux and temperature balance wlll over be attalned. One of the easlest mistakes to make in reactor control is to assume that once good temperature balance is established 1t will remain constant. In each of the "small p1le" sections of the reactor there 18 a tendency for the neutron flux density to vary with time according to 1ts previous operating history. Th1s causes the flux to rock or cycle from region to region, and unless constant corrections are made 
93. (Continued)

Answer: (Continued)

these temperature cycles soon become large and difficult to control. Perhaps the most prevalent error made 18 to hesitate in applying control to a flux situation because of indec1s1on. During this period of indocision the reactor is essentially being allowed to drift out of distribution control, the flux charge 18 allowed to "snowball" and the longer it $1 \mathrm{~s}$ left uncorrected the more difficult It 18 to correct.

94. If the neutron IIux 18 constantly moving from region to region in the pile and each movement varles with time, how can the correct control rod be selected at the right time for any given plle condition?

Answer: The possibility of selecting the wrong control for any pile condition can be considerably reduced through the proposed temperature sampling work sheets (see answer to questions 86 thru 90). The work sheets are not intended as a substitute for any monitoring or operating procedure, but rather as a method of developing a better understanding of the two basic principles of reactor control-maximum tube outlet temperature and flux (temperature) distribution. The method can be briefly sumarized in four basic steps:

(a) Set up tube outlet temperature work sheets as 1llustrated in P1gure 24 of Chapter V, IPD Phys1cs Primer.

(b) Set up graphite temperature work sheets as 11lustrated in Figure 25.

(c) Record sampling data at twenty-minute time intervals to establish temperature trends.

(d) Cross-check valldity of all tube and graphite temperature data with octant monitor and Beckman readings.

The work sheet sampling data should be used in conjunction with all other monitoring instrumentation. It 18 imperative that information from all sources be observed and correlated before, during, and after all control rod movement. When used in this manner, every rod selection 1 s based on control data from a varlety of sources, results and performance can be evaluated, and "feel" for reactor control can be developed.

95. Which is more important, accurate instrumentation or good control techniques?

Answer: Both are equaliy important; the Information gained from the 1nstruments must be converted 1nto good control techniques in order to operate the reactor in a safe and efficlent manner. Both of these responsibilities rest squarely in the hands of the people operating 


\section{5. (Continued)}

\section{DECLLSSFFIED}

Answer: (Continued)

the reactor. An enormous amount of excellent data, taken at the most advantageous time by the most accurate of instruments, are generally useless unless appropriate control action is taken. Data must be taken, understood, and interpreted in the form of action. Understanding of these data can at times be difficult and deciding on the correct action at the proper time even more so. Plans must be made to detect and follow smail temperature shifts and flux tendencles, and the proper action Initiated to correct them as soon as possible.

96. What type of knowledge is required to operate reactor safely and efficlently.?

Answer: Operating "know-how" Involves a thorough understanding of the nuclear process and monitoring instrumentation; knowing at all times what is going on, and then exercising judgement and discretion. In order to plan intelligently, an operator must keep in mind at all times the changes wh1ch have occurred, the changes taking place, the expected results of these changes, and the correct action to take to maintain or improve the flux distribution. To operate safely, he must have adequate coptrol data on which to base his judgement and he must know the operating 11 mits at all t1mes. To operate efficlently, he must approach these Iimits In a wise and safe manner, guiding the reactor through the varlous operating conditions to an optimum level of safety and efficlency. 

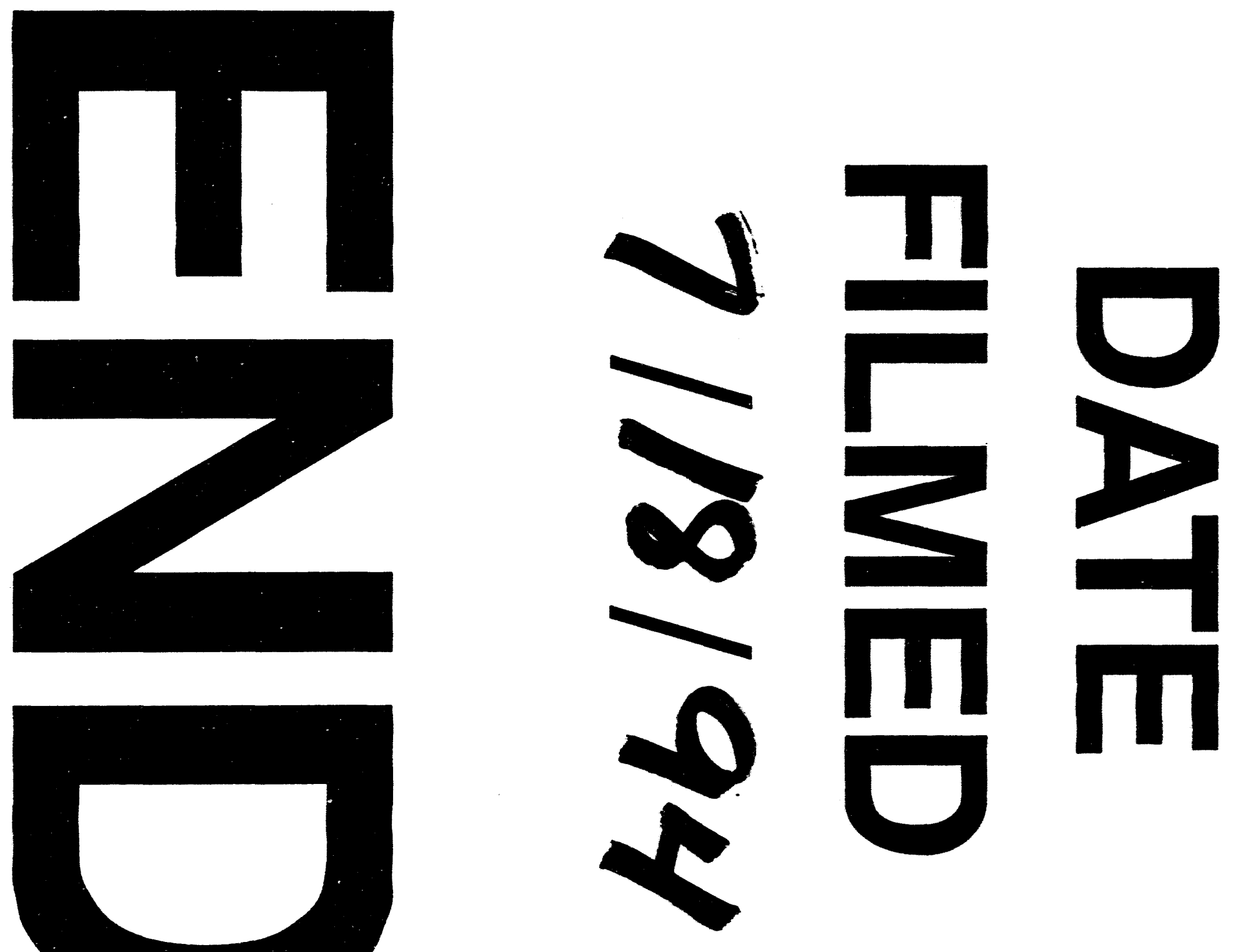

且

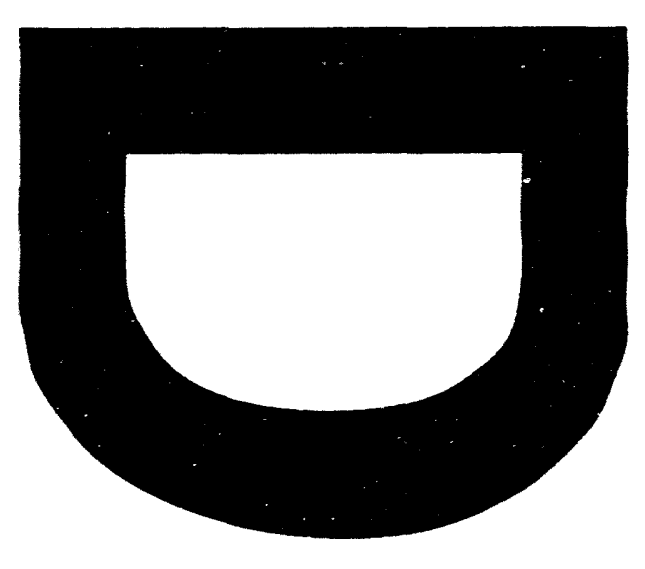


